\title{
Modified Variational Iteration Method for Free-Convective Boundary-Layer Equation Using Padé Approximation
}

\author{
Syed Tauseef Mohyud-Din, ${ }^{1}$ Ahmet Yildirim, ${ }^{2}$ \\ Sefa Anıl Sezer, ${ }^{2}$ and Muhammad Usman ${ }^{3}$ \\ ${ }^{1}$ HITEC University, Taxila Cantt, Pakistan \\ ${ }^{2}$ Department of Mathematics, Ege University, Bornova 35100, Izmir, Turkey \\ ${ }^{3}$ Department of Mathematics, University of Dayton, 300 College Park, Dayton, OH 45469-2316, USA
}

Correspondence should be addressed to Syed Tauseef Mohyud-Din, syedtauseefs@hotmail.com

Received 16 October 2009; Accepted 17 January 2010

Academic Editor: Jihuan He

Copyright (c) 2010 Syed Tauseef Mohyud-Din et al. This is an open access article distributed under the Creative Commons Attribution License, which permits unrestricted use, distribution, and reproduction in any medium, provided the original work is properly cited.

This paper is devoted to the study of a free-convective boundary-layer flow modeled by a system of nonlinear ordinary differential equations. We apply a modified variational iteration method (MVIM) coupled with He's polynomials and Padé approximation to solve freeconvective boundary-layer equation. It is observed that the combination of MVIM and the Padé approximation improves the accuracy and enlarges the convergence domain.

\section{Introduction}

The boundary-layer flows of viscous fluids are of utmost importance for industry and applied sciences. These flows can be modeled by systems of nonlinear ordinary differential equations on an unbounded domain, see [1-4] and the references therein. Keeping in view the physical importance of such problems, there is a dire need of extension of some reliable and efficient technique for the solution of such problems. He [1, 2, 5-15] developed the variational iteration (VIM) and homotopy perturbation (HPM) methods which are very efficient and accurate and are $[1,2,4-42]$ being used very frequently for finding the appropriate solutions of nonlinear problems of physical nature. In a later work, Ghorbani and Nadjfi [24] introduced He's polynomials which are calculated for He's homotopy perturbation method. It is also established [24] that He's polynomials are compatible with Adomian's polynomials but are easier to implement and are more user friendly. Recently, Mohyud-Din, Noor and Noor [4, 33-36] made the elegant coupling of He's polynomials and the correction functional of 
variational iteration method (VIM) and found the solutions of number of nonlinear singular and nonsingular problems. It is observed that $[4,33-36]$ the modified version of VIM is very efficient in solving nonlinear problems. The basic motivation of this paper is the extension of the modified variational iteration method (MVIM) coupled with Padé approximation to solve a free-convective boundary-layer flow modeled by a system of nonlinear ordinary differential equations. Numerical and figurative illustrations show that it is a promising tool to solve nonlinear problems. It needs to be highlighted that Herisanu and Marinca [41] suggested an optimal variational iteration algorithm. It needs to be highlighted that He in his latest article "The variational iteration method which should be followed" [42] presented a very comprehensive and detailed study on various aspects of variational iteration method in connection with partial differential equations, ordinary differential equations, fractional differential equations, fractal-differential equations, and difference-differential equations.

\section{Modified Variational Iteration Method (MVIM)}

To illustrate the basic concept of the modified variational iteration method (MVIM), we consider the following general differential equation:

$$
L u+N u=g(x)
$$

where $L$ is a linear operator, $N$ is a nonlinear operator, and $g(x)$ is the forcing term. According to variational iteration method $[1,2,4,10-23,28,33-39,41,42]$, we can construct a correction functional as follows:

$$
u_{n+1}(x)=u_{n}(x)+\int_{0}^{x} \lambda(\xi)\left(L u_{n}(\xi)+N \tilde{u}_{n}(\xi)-g(\xi)\right) d \xi
$$

where $\mathcal{l}$ is a Lagrange multiplier $[1,2,10-15,42]$, which can be identified optimally via variational iteration method. The subscripts $n$ denote the $n$th approximation; $\tilde{u}_{n}$ is considered as a restricted variation. That is, $\delta \tilde{u}_{n}=0 ;(2.2)$ is called a correction functional. Now, we apply He's polynomials [24]

$$
\sum_{n=0}^{\infty} p^{(n)} u_{n}=u_{0}(x)+p \int_{0}^{x} \lambda(\xi)\left(\sum_{n=0}^{\infty} p^{(n)} L\left(u_{n}\right)+\sum_{n=0}^{\infty} p^{(n)} N\left(\tilde{u}_{n}\right)\right) d \xi-\int_{0}^{x} \lambda(\xi) g(\xi) d \xi
$$

which is the coupling of variational iteration method and He's polynomials and is called the modified variational iteration method (MVIM) [4, 33-36]. The comparison of like powers of $p$ gives solutions of various orders. 


\section{Mathematical Model}

Let us consider the problem of cooling of a low-heat-resistance sheet that moves downwards in a viscous fluid [3]:

$$
\begin{gathered}
\frac{\partial u}{\partial x}+\frac{\partial v}{\partial y}=0 \\
u \frac{\partial u}{\partial x}+v \frac{\partial u}{\partial y}=v \frac{\partial^{2} u}{\partial y^{2}}+g \beta\left(T-T_{0}\right) \\
u \frac{\partial T}{\partial x}+v \frac{\partial T}{\partial y}=\kappa \frac{\partial^{2} T}{\partial y^{2}}
\end{gathered}
$$

subject to

$$
\begin{gathered}
u=0, \quad v=0 \quad \text { at } y=0, \\
u \longrightarrow 0, \quad T \longrightarrow T_{0} \quad \text { as } y \longrightarrow \infty,
\end{gathered}
$$

where $u$ and $v$ are the velocity components in the $x$ - and $y$-directions, respectively. $\psi T$ is the temperature, $T_{0}$ is the temperature of the surrounding fluid, $v$ is the kinematic viscosity, $\kappa$ is the thermal diffusivity, $g$ is the acceleration due to gravity, and $\beta$ is the coefficient of thermal expansion. Using the similarity variables

$$
\begin{gathered}
\psi=\left[g \beta\left(T_{1}-T_{0}\right) v^{2} x_{0}^{3}\right]^{1 / 4} f(\eta), \\
T=T_{0}+\left(T_{1}-T_{0}\right)\left[\frac{x_{0}}{\left(x_{0}-x\right)}\right]^{3} \theta(\eta), \\
\eta=\left[\frac{g \beta\left(T_{1}-T_{0}\right) x_{0}^{3}}{v^{2}}\right]^{1 / 4} \frac{y}{\left(x_{0}-x\right)},
\end{gathered}
$$

where $\psi$ is the stream function defined by $u=\partial \psi / \partial y$ and $v=-\partial \psi / \partial x, f$ and $\theta$ are the similarity functions dependent on $\eta, T(0,0)=T_{1}$ and $\theta(0)=1,(3.1)$ is transformed to

$$
\begin{gathered}
f^{\prime \prime \prime}(\eta)+\theta(\eta)-\left(f^{\prime}(\eta)\right)^{2}=0 \\
\theta^{\prime \prime}(\eta)-3 \sigma f^{\prime}(\eta) \theta(\eta)=0
\end{gathered}
$$

subject to the boundary conditions

$$
\begin{gathered}
f(0)=0, \quad f^{\prime}(0)=0, \quad f^{\prime}(+\infty)=0, \\
\theta(0)=1, \quad \theta(+\infty)=0,
\end{gathered}
$$

where the primes denote differentiation with respect to $\eta$, and $\sigma$ is the Prandtl number. 
Table 1: Numerical values of $\alpha_{1}=f^{\prime \prime}(0)$.

\begin{tabular}{lcccc}
\hline$\sigma$ & {$[4,4]$} & {$[5,5]$} & {$[6,6]$} & $\alpha_{1}$ \\
\hline 0.001 & 1.1135529418 & 1.1272760416 & 1.1252849854 & 1.1231381347 \\
0.01 & 1.0631737963 & 1.0741895683 & 1.0638385351 & 1.0633808585 \\
0.1 & 0.9128082210 & 0.9238226280 & 0.9242158493 & 0.9240830397 \\
1 & 0.6941230861 & 0.6929598014 & 0.6932195158 & 0.6932116298 \\
10 & 0.4511240728 & 0.4502429544 & 0.4476712316 & 0.4471165250 \\
100 & 0.2679197151 & 0.2681474363 & 0.2641295627 & 0.2645235434 \\
1000 & 0.2204061432 & 0.1524783266 & 0.1500456755 & 0.1512901971 \\
10000 & 0.0858587180 & 0.0858519249 & 0.0844775473 & 0.0855408524 \\
\hline
\end{tabular}

Table 2: Numerical values of $\alpha_{2}=\theta^{\prime}(0)$.

\begin{tabular}{lcccc}
\hline$\sigma$ & {$[4,4]$} & {$[5,5]$} & {$[6,6]$} & $\alpha_{2}$ of $[3]$ \\
\hline 0.001 & -0.0371141028 & -0.0415417739 & -0.0436188230 & -0.0468074648 \\
0.01 & -0.1274922800 & -0.1221616907 & -0.1351353865 & -0.1357607439 \\
0.1 & -0.3621215470 & -0.3505589981 & -0.3499273453 & -0.3500596733 \\
1 & -0.7694165843 & -0.7695971295 & -0.7698955992 & -0.7698611967 \\
10 & -1.5028543431 & -1.5007437650 & -1.4985484075 & -1.4970992078 \\
100 & -2.7627624234 & -2.7637067330 & -2.7445541894 & -2.7468855016 \\
1000 & -5.7787858408 & -4.9468469883 & -4.9104728566 & -4.9349476252 \\
10000 & -8.8057265644 & -8.8032691004 & -8.7384279086 & -8.8044492660 \\
\hline
\end{tabular}

\section{The Padé Approximation}

We denote $L, M$ Padé approximants to $f(z)$ by

$$
\left[\frac{L}{M}\right]=\frac{P_{L}(z)}{Q_{M}(z)},
$$

where $P_{L}(z)$ is polynomial of degree at most $L$ and $Q_{M}(z)\left(Q_{M}(z) \neq 0\right)$ is a polynomial of degree at most $M$. The former power series is

$$
f(z)=\sum_{k=0}^{\infty} c_{k} \cdot z^{k}
$$

And we write the $P_{L}(z)$ and $Q_{M}(z)$ as

$$
\begin{gathered}
P_{L}(z)=p_{0}+p_{1} \cdot z+p_{2} \cdot z^{2}+p_{3} \cdot z^{3}+\cdots+p_{L} \cdot z^{L} \\
Q_{M}(z)=q_{0}+q_{1} \cdot z+q_{2} \cdot z^{2}+q_{3} \cdot z^{3}+\cdots+q_{M} \cdot z^{M}
\end{gathered}
$$

so

$$
f(z)-\frac{P_{L}(z)}{Q_{M}(z)}=O\left(z^{L+M+1}\right) \text { as } z \longrightarrow 0,
$$




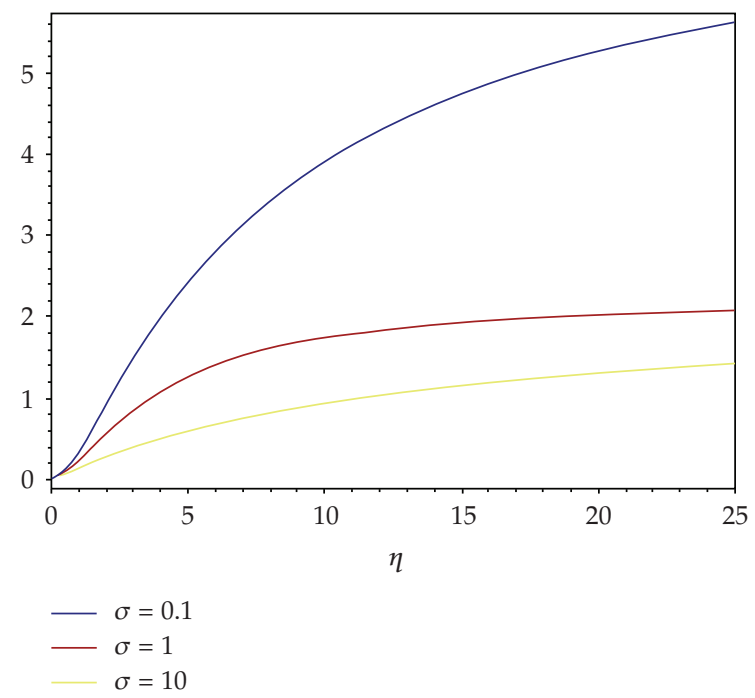

Figure 1: Variation of $f(\eta)$ using $\phi_{6[6,6]}$ for $\sigma=0.1, \phi_{6[5,5]}$ for $\sigma=1$, and $\phi_{6[4,4]}$ for $\sigma=10$.

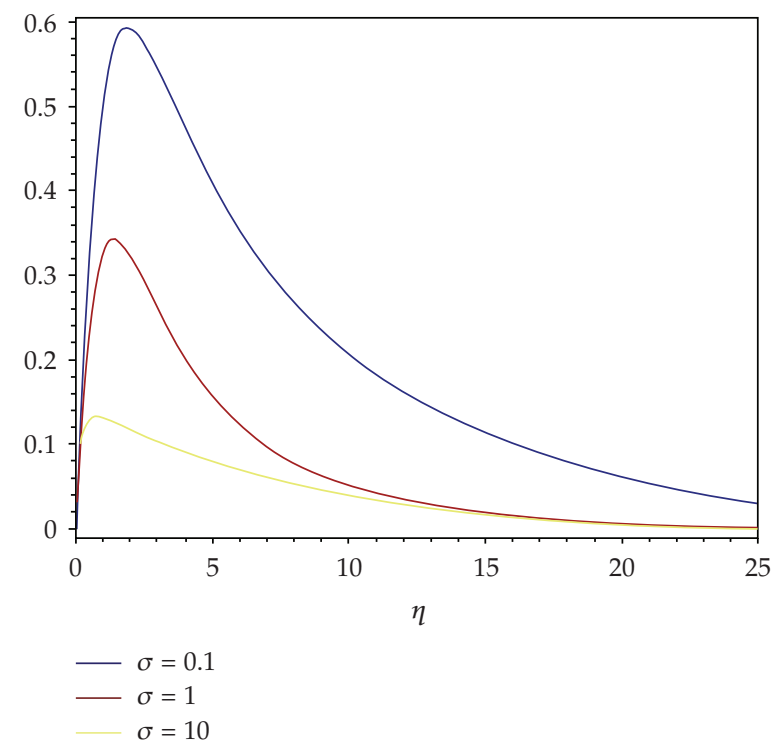

Figure 2: Variation of $f^{\prime}(\eta)$ using $\phi_{6[6,6]}$ for $\sigma=0.1, \phi_{6[5,5]}$ for $\sigma=1$, and $\phi_{6[4,4]}$ for $\sigma=10$.

and the coefficients of $P_{L}(z)$ and $Q_{M}(z)$ are determined by the equation. From (4.4), we have

$$
f(z) \cdot Q_{M}(z)-P_{L}(z)=O\left(z^{L+M+1}\right)
$$




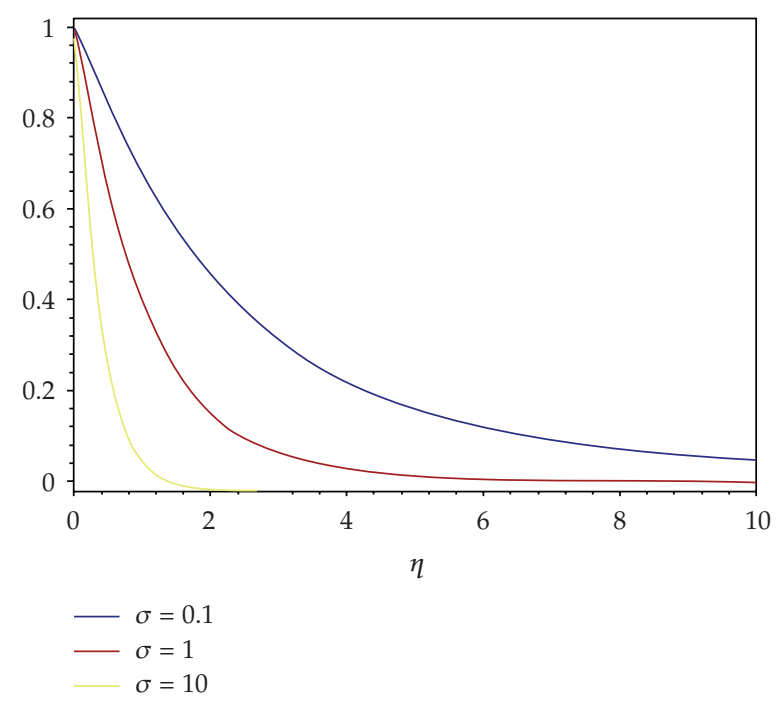

Figure 3: Variation of $\theta(\eta)$ using $\varpi_{7[6,6]}$ for $\sigma=0.1, \varpi_{7[5,5]}$ for $\sigma=1$ and $\phi_{7[4,4]}$ for $\sigma=10$.

which system of $L+M+1$ homogeneous equations with $L+M+2$ unknown quantities. We impose the normalization condition

$$
Q_{M}(0)=1
$$

We can write out (4.5) as

$$
\begin{gathered}
c_{L+1}+c_{L} \cdot q_{1}+\cdots+c_{L-M+1} \cdot q_{M}=0 \\
c_{L+2}+c_{L+1} \cdot q_{1}+\cdots+c_{L-M+2} \cdot q_{M}=0 \\
\vdots \\
c_{L+M}+c_{L+M-1} \cdot q_{1}+\cdots+c_{L} \cdot q_{M}=0 \\
c_{0}=p_{0} \\
c_{1}+c_{0} \cdot q_{1}=p_{1} \\
c_{2}+c_{1} \cdot q_{1}+c_{0} \cdot q_{2}=p_{2} \\
\vdots \\
c_{L}+c_{L-1} \cdot q_{1}+\cdots+c_{0} \cdot q_{L}=p_{L} .
\end{gathered}
$$

From (4.7), we can obtain $q_{i}(1 \leq i \leq M)$. Once the values of $q_{1}, q_{2}, \ldots, q_{M}$ are all known (4.8) gives an explicit formula for the unknown quantities $p_{1}, p_{2}, \ldots, p_{L}$. For the diagonal approximants like $[2 / 2],[3 / 3],[4 / 4],[5 / 5]$, or [6/6] have the most accurate approximants by built-in utilities of Maple. 


\section{Solution Procedure}

Consider problems (3.4)-(3.5) formulated in Section 3 and is related to the free-convective boundary-layer flow.

The correction functional is given by

$$
\begin{aligned}
& f_{n+1}(\eta)=f_{n}(\eta)+\int_{0}^{x} \lambda_{1}(s)\left(\frac{d^{3} f_{n}}{d s^{3}}+\tilde{\theta}_{n}(\eta)-\left(\frac{d \tilde{f}_{n}}{d \eta}\right)^{2}\right) d s \\
& \theta_{n+1}(\eta)=\theta_{n}(\eta)+\int_{0}^{x} \lambda_{2}(s)\left(\frac{d^{2} \theta_{n}}{d s^{2}}-3 \sigma\left(\frac{d \tilde{f}_{n}}{d \eta}\right)\right) \tilde{\theta}_{n}(\eta) d s .
\end{aligned}
$$

Making the correction functional stationary, the Lagrange multipliers can easily be identified

$$
\lambda_{1}(s)=-\frac{1}{2 !}(s-\eta)^{2}, \quad \lambda_{2}(s)=(s-\eta)
$$

Consequently,

$$
\begin{gathered}
f_{n+1}(\eta)=f_{n}(\eta)-\int_{0}^{x} \frac{1}{2 !}(s-\eta)^{2}\left(\frac{d^{3} f_{n}}{d s^{3}}+\theta_{n}(\eta)-\left(\frac{d f_{n}}{d \eta}\right)^{2}\right) d s \\
\theta_{n+1}(\eta)=\theta_{n}(\eta)+\int_{0}^{x}(s-\eta)\left(\frac{d^{2} \theta_{n}}{d s^{2}}-3 \sigma\left(\frac{d f_{n}}{d \eta}\right)\right) \theta_{n}(\eta) d s .
\end{gathered}
$$

Applying the modified variational iteration method (MVIM), we get

$$
\begin{gathered}
f_{0}+p f_{1}+\cdots=f_{0}(\eta)-p \int_{0}^{x} \frac{1}{2 !}(s-\eta)^{2}\left(\left(\frac{d^{3} f_{0}}{d s^{3}}+p \frac{d^{3} f_{1}}{d s^{3}}+\cdots\right)+\left(\theta_{0}+p \theta_{1}+\cdots\right)\right. \\
\left.-\left(\frac{d f_{0}}{d \eta}+p \frac{d f_{1}}{d \eta}+\cdots\right)^{2}\right) d s \\
\theta_{0}+p \theta_{1}+\cdots=\theta_{0}(\eta)+\int_{0}^{x}(s-\eta)\left(\left(\frac{d^{2} \theta_{0}}{d s^{2}}+p \frac{d^{2} \theta_{1}}{d s^{2}}+\cdots\right)-3 \sigma\left(\theta_{0}+p \theta_{1}+\cdots\right)\right. \\
\left.-\left(\frac{d f_{0}}{d \eta}+p \frac{d f_{1}}{d \eta}+\cdots\right)^{2}\right) d s .
\end{gathered}
$$


Comparing the coefficient of like powers of $p$, we get

$$
\begin{aligned}
& p^{0}: f_{0}(\eta)=\left(\frac{\alpha_{1}}{2}\right) \eta^{2} \\
& p^{1}: f_{1}(\eta)=\left(\frac{\alpha_{1}}{2}\right) \eta^{2}-\left(\frac{1}{6}\right) \eta^{3}+\left(\frac{\alpha_{2}}{24}\right) \eta^{4}+\left(\frac{\alpha_{1}^{2}}{60}\right) \eta^{5} \\
& p^{2}: f_{2}(\eta)=\left(\frac{\alpha_{1}}{2}\right) \eta^{2}-\left(\frac{1}{6}\right) \eta^{3}+\left(\frac{\alpha_{2}}{24}\right) \eta^{4}+\left(\frac{\alpha_{1}^{2}}{60}\right) \eta^{5}-\left(\frac{\sigma \alpha_{1}}{240}+\frac{\alpha_{1}}{120}\right) \eta^{6} \\
& +\left(\frac{\alpha_{1} \alpha_{2}}{630}+\frac{\sigma \alpha_{1} \alpha_{2}}{120}\right) \eta^{7}+\left(\frac{\alpha_{1}^{3}}{2016}\right) \eta^{8} \\
& p^{3}: f_{3}(\eta)=\left(\frac{\alpha_{1}}{2}\right) \eta^{2}-\left(\frac{1}{6}\right) \eta^{3}+\left(\frac{\alpha_{2}}{24}\right) \eta^{4}+\left(\frac{\alpha_{1}^{2}}{60}\right) \eta^{5}-\left(\frac{\sigma \alpha_{1}}{240}+\frac{\alpha_{1}}{120}\right) \eta^{6} \\
& +\left(\frac{\alpha_{1} \alpha_{2}}{630}+\frac{\sigma \alpha_{1} \alpha_{2}}{120}+\frac{\sigma}{1680}+\frac{1}{840}\right) \eta^{7} \\
& +\left(\frac{\alpha_{1}^{3}}{2016}+\frac{\sigma \alpha_{2}}{3360}+\frac{\alpha_{2}}{2016}\right) \eta^{8}+\left(-\frac{\alpha_{1}^{2} \sigma^{2}}{10080}+\frac{\alpha_{1}^{2} \sigma}{8640}+\frac{\sigma \alpha_{2}^{2}}{130240}-\frac{11 \alpha_{1}^{2}}{30240}+\frac{\alpha_{2}^{2}}{18144}\right) \eta^{9} \\
& +\left(-\frac{\alpha_{1}^{2} \alpha_{2}}{14400}-\frac{19 \alpha_{1}^{2} \sigma \alpha_{2}}{604800}-\frac{\alpha_{1}^{2} \sigma^{2} \alpha_{2}}{40320}\right) \eta^{10} \\
& \vdots \\
& p^{0}: \theta_{0}(\eta)=1+\left(\alpha_{2}\right) \eta \\
& p^{1}: \theta_{1}(\eta)=1+\alpha_{2} \eta+\left(\frac{\sigma \alpha_{1} \alpha_{2}}{2}\right) \eta^{3}+\left(\frac{\sigma \alpha_{1} \alpha_{2}}{4}\right) \eta^{4}, \\
& p^{2}: \theta_{2}(\eta)=1+\alpha_{2} \eta+\left(\frac{\sigma \alpha_{1} \alpha_{2}}{2}\right) \eta^{3}+\left(\frac{\sigma \alpha_{1} \alpha_{2}}{4}\right) \eta^{4}-\left(\frac{\alpha_{1} \alpha_{2}}{10}\right) \eta^{5}+\left(\frac{\alpha_{1}^{2} \sigma^{2}}{20}+\frac{\alpha_{1}^{2} \sigma}{120}-\frac{\alpha_{2}^{2} \sigma}{60}\right) \eta^{6} \\
& \times\left(\frac{\alpha_{1}^{2} \sigma \alpha_{2}}{168}+\frac{\alpha_{1}^{2} \alpha_{2} \sigma^{2}}{56}\right) \eta^{7} \\
& p^{3}: \theta_{3}(\eta)=1+\alpha_{2} \eta+\left(\frac{\sigma \alpha_{1} \alpha_{2}}{2}\right) \eta^{3}+\left(\frac{\sigma \alpha_{1} \alpha_{2}}{4}\right) \eta^{4}-\left(\frac{\alpha_{1} \alpha_{2}}{10}\right) \eta^{5}+\left(\frac{\alpha_{1}^{2} \sigma^{2}}{20}+\frac{\alpha_{1}^{2} \sigma}{120}-\frac{\alpha_{2}^{2} \sigma}{60}\right) \eta^{6} \\
& +\left(\frac{\alpha_{1}^{2} \sigma \alpha_{2}}{168}+\frac{\alpha_{1}^{2} \alpha_{2} \sigma^{2}}{56}-\frac{\sigma \alpha_{1}}{280}-\frac{\alpha_{1} \sigma^{2}}{35}\right) \eta^{7}+\left(-\frac{11 \alpha_{1} \sigma \alpha_{2}}{3360}-\frac{41 \alpha_{1} \sigma^{2} \alpha_{2}}{2240}\right) \eta^{8} \\
& +\left(\frac{\alpha_{1}^{2} \sigma^{2} \alpha_{2}^{2}}{360}+\frac{\alpha_{1}^{2} \sigma}{6048}+\frac{\sigma^{3} \alpha_{1}^{3}}{480}-\frac{\alpha_{1} \alpha_{2}^{2} \sigma}{2160}\right) \eta^{9}
\end{aligned}
$$




$$
\begin{aligned}
& +\left(\frac{\alpha_{1}^{3} \alpha_{2} \sigma \alpha_{2}^{2}}{7560}+\frac{\alpha_{1}^{2} \sigma^{2} \alpha_{2}}{1120}+\frac{\sigma^{3} \alpha_{2} \alpha_{1}^{3}}{1680}\right) \eta^{10}, \\
& \vdots
\end{aligned}
$$

The series solution is given by

$$
\begin{aligned}
f(\eta)= & \left(\frac{\alpha_{1}}{2}\right) \eta^{2}-\left(\frac{1}{6}\right) \eta^{3}+\left(\frac{\alpha_{2}}{24}\right) \eta^{4}+\left(\frac{\alpha_{1}^{2}}{60}\right) \eta^{5}-\left(\frac{\sigma \alpha_{1}}{240}+\frac{\alpha_{1}}{120}\right) \eta^{6} \\
& +\left(\frac{\alpha_{1} \alpha_{2}}{630}+\frac{\sigma \alpha_{1} \alpha_{2}}{120}+\frac{\sigma}{1680}+\frac{1}{840}\right) \eta^{7} \\
& +\left(\frac{\alpha_{1}^{3}}{2016}+\frac{\sigma \alpha_{2}}{3360}+\frac{\alpha_{2}}{2016}\right) \eta^{8}+\left(-\frac{\alpha_{1}^{2} \sigma^{2}}{10080}+\frac{\alpha_{1}^{2} \sigma}{8640}+\frac{\sigma \alpha_{2}^{2}}{130240}-\frac{11 \alpha_{1}^{2}}{30240}+\frac{\alpha_{2}^{2}}{18144}\right) \eta^{9} \\
& +\left(-\frac{\alpha_{1}^{2} \alpha_{2}}{14400}-\frac{19 \alpha_{1}^{2} \sigma \alpha_{2}}{604800}-\frac{\alpha_{1}^{2} \sigma^{2} \alpha_{2}}{40320}\right) \eta^{10}+\cdots, \\
\theta(\eta)= & +\alpha_{2} \eta+\left(\frac{\sigma \alpha_{1} \alpha_{2}}{2}\right) \eta^{3}+\left(\frac{\sigma \alpha_{1} \alpha_{2}}{4}\right) \eta^{4}-\left(\frac{\alpha_{1} \alpha_{2}}{10}\right) \eta^{5}+\left(\frac{\alpha_{1}^{2} \sigma^{2}}{20}+\frac{\alpha_{1}^{2} \sigma}{120}-\frac{\alpha_{2}^{2} \sigma}{60}\right) \eta^{6} \\
& +\left(\frac{\alpha_{1}^{2} \sigma \alpha_{2}}{168}+\frac{\alpha_{1}^{2} \alpha_{2} \sigma^{2}}{56}-\frac{\sigma \alpha_{1}}{280}-\frac{\alpha_{1} \sigma^{2}}{35}\right) \eta^{7}+\left(-\frac{11 \alpha_{1} \sigma \alpha_{2}}{3360}-\frac{41 \alpha_{1} \sigma^{2} \alpha_{2}}{2240}\right) \eta^{8} \\
& +\left(\frac{\alpha_{1}^{2} \sigma^{2} \alpha_{2}^{2}}{360}+\frac{\alpha_{1}^{2} \sigma}{6048}+\frac{\sigma^{3} \alpha_{1}^{3}}{480}-\frac{\alpha_{1} \alpha_{2}^{2} \sigma}{2160}\right) \eta^{9} \\
& +\left(\frac{\alpha_{1}^{3} \alpha_{2} \sigma \alpha_{2}^{2}}{7560}+\frac{\alpha_{1}^{2} \sigma^{2} \alpha_{2}}{1120}+\frac{\sigma^{3} \alpha_{2} \alpha_{1}^{3}}{1680}\right) \eta^{10}+\cdots
\end{aligned}
$$

It is observed in Figures 1 and 2 that the flow has a boundary-layer structure and the thickness of this boundary-layer decreases with increase in the Prandtl number, $\sigma$ as expected. This is due to the inhibiting influence of the viscous forces.

Figure 3 shows the increase of the Prandtl number, $\sigma$, that results in the decrease, as expected, of temperature distribution at a particular point of the flow region, that is, there would be a decrease of the thermal boundary-layer thickness with the increase of values of $\sigma$ implying a slow rate of thermal diffusion. Thus higher Prandtl number $\sigma$ leads to faster cooling of the plane sheet.

\section{Conclusions}

In this study, we employed modified variational iteration method (MVIM) coupled with Padé approximation to solve a system of two nonlinear ordinary differential equations that describes a free-convective boundary-layer in glass-fiber production process. The results 
show strong effects of the Prandtl number on the velocity and temperature profiles since the two model equations are coupled.

\section{Acknowledgment}

The authors are highly grateful to the referee for his/her very constructive comments.

\section{References}

[1] J. H. He, "An elementary introduction of recently developed asymptotic methods and nanomechanics in textile engineering," International Journal of Modern Physics B, vol. 22, no. 21, pp. 3487-4578, 2008.

[2] J.-H. He, "Some asymptotic methods for strongly nonlinear equations," International Journal of Modern Physics B, vol. 20, no. 10, pp. 1141-1199, 2006.

[3] S. A. Kechil and I. Hashim, "Non-perturbative solution of free-convective boundary-layer equation by adomian decomposition method," Physics Letters A, vol. 363, pp. 110-114, 2007.

[4] S. T. Mohyud-Din, M. A. Noor, and K. I. Noor, "Some relatively new techniques for nonlinear problems," Mathematical Problems in Engineering, vol. 2009, Article ID 234849, 25 pages, 2009.

[5] J.-H. He, "Recent development of the homotopy perturbation method," Topological Methods in Nonlinear Analysis, vol. 31, no. 2, pp. 205-209, 2008.

[6] J.-H. He, "Comparison of homotopy perturbation method and homotopy analysis method," Applied Mathematics and Computation, vol. 156, no. 2, pp. 527-539, 2004.

[7] J. H. He, "Homotopy perturbation method for bifurcation of nonlinear problems," International Journal of Nonlinear Science and Numerical Simulation, vol. 6, no. 2, pp. 207-208, 2005.

[8] J.-H. He, "The homotopy perturbation method nonlinear oscillators with discontinuities," Applied Mathematics and Computation, vol. 151, no. 1, pp. 287-292, 2004.

[9] J.-H. He, "A coupling method of a homotopy technique and a perturbation technique for non-linear problems," International Journal of Non-Linear Mechanics, vol. 35, no. 1, pp. 37-43, 2000.

[10] J.-H. He, "Variational iteration method—some recent results and new interpretations," Journal of Computational and Applied Mathematics, vol. 207, no. 1, pp. 3-17, 2007.

[11] J. H. He, "Variational iteration method, a kind of non-linear analytical technique, some examples," International Journal of Non-Linear Mechanics, vol. 34, no. 4, pp. 699-708, 1999.

[12] J.-H. He, "Variational iteration method for autonomous ordinary differential systems," Applied Mathematics and Computation, vol. 114, no. 2-3, pp. 115-123, 2000.

[13] J.-H. He, "The variational iteration method for eighth-order initial-boundary value problems," Physica Scripta, vol. 76, no. 6, pp. 680-682, 2007.

[14] J.-H. He and X.-H. Wu, "Variational iteration method: new development and applications," Computers E Mathematics with Applications, vol. 54, no. 7-8, pp. 881-894, 2007.

[15] J.-H. He and X.-H. Wu, "Construction of solitary solution and compacton-like solution by variational iteration method," Chaos, Solitons E Fractals, vol. 29, no. 1, pp. 108-113, 2006.

[16] S. Abbasbandy, "A new application of He's variational iteration method for quadratic Riccati differential equation by using Adomian's polynomials," Journal of Computational and Applied Mathematics, vol. 207, no. 1, pp. 59-63, 2007.

[17] S. Abbasbandy, "Numerical solution of non-linear Klein-Gordon equations by variational iteration method," International Journal for Numerical Methods in Engineering, vol. 70, no. 7, pp. 876-881, 2007.

[18] M. A. Abdou and A. A. Soliman, "Variational iteration method for solving Burger's and coupled Burger's equations," Journal of Computational and Applied Mathematics, vol. 181, no. 2, pp. 245-251, 2005.

[19] M. A. Abdou and A. A. Soliman, “New applications of variational iteration method," Physica D, vol. 211, no. 1-2, pp. 1-8, 2005.

[20] T. A. Abassy, M. A. El-Tawil, and H. El Zoheiry, "Solving nonlinear partial differential equations using the modified variational iteration Padé technique," Journal of Computational and Applied Mathematics, vol. 207, no. 1, pp. 73-91, 2007.

[21] B. Batiha, M. S. M. Noorani, and I. Hashim, "Variational iteration method for solving multispecies Lotka-Volterra equations," Computers \& Mathematics with Applications, vol. 54, no. 7-8, pp. 903-909, 2007. 
[22] J. Biazar and H. Ghazvini, "He's variational iteration method for fourth-order parabolic equations," Computers \& Mathematics with Applications, vol. 54, no. 7-8, pp. 1047-1054, 2007.

[23] D. D. Ganji, H. Tari, and M. B. Jooybari, "Variational iteration method and homotopy perturbation method for nonlinear evolution equations," Computers \& Mathematics with Applications, vol. 54, no. 7-8, pp. 1018-1027, 2007.

[24] A. Ghorbani and J. S. Nadjfi, "He's homotopy perturbation method for calculating Adomian's polynomials," International Journal of Nonlinear Science and Numerical Simulation, vol. 8, no. 2, pp. 229 332, 2007.

[25] M. Javidi and A. Golbabai, "A variational iteration method for solving parabolic partial differential equations," Computers \& Mathematics with Applications, vol. 54, no. 7-8, pp. 1003-1009, 2007.

[26] J. Lu, "Variational iteration method for solving two-point boundary value problems," Journal of Computational and Applied Mathematics, vol. 207, no. 1, pp. 92-95, 2007.

[27] W.-X. Ma, H. Y. Wu, and J. S. He, "Partial differential equations possessing Frobenius integrable decompositions," Physics Letters A, vol. 364, no. 1, pp. 29-32, 2007.

[28] S. Momani and Z. Odibat, "Application of He's variational iteration method to Helmholtz equation," Chaos, Solitons \& Fractals, vol. 27, no. 5, pp. 1119-1123, 2006.

[29] T. Mohyud-Din, M. A. Noor, and K. I. Noor, "Travelling wave solutions of seventh-order generalized $\mathrm{KdV}$ equations using He's polynomials," International Journal of Nonlinear Sciences and Numerical Simulation, vol. 10, no. 2, pp. 223-229, 2009.

[30] S. T. Mohyud-Din and M. A. Noor, "Homotopy perturbation method for solving fourth-order boundary value problems," Mathematical Problems in Engineering, vol. 2007, Article ID 98602, 15 pages, 2007.

[31] S. T. Mohyud-Din and M. A. Noor, "Homotopy perturbation method for solving partial differential equations," Zeitschrift für Naturforschung A, vol. 64, pp. 157-170, 2009.

[32] S. T. Mohyud-Din, M. A. Noor, and K. I. Noor, "Parameter-expansion techniques for strongly nonlinear oscillators," International Journal of Nonlinear Sciences and Numerical Simulation, vol. 10, no. 5, pp. 581-583, 2009.

[33] S. T. Mohyud-Din, M. A. Noor, and K. I. Noor, “On the coupling of polynomials with correction functional," International Journal of Modern Physics B. In press.

[34] S. T. Mohyud-Din, "Solving heat and wave-like equations using He's polynomials," Mathematical Problems in Engineering, vol. 2009, Article ID 427516, 12 pages, 2009.

[35] M. A. Noor and S. T. Mohyud-Din, "Variational iteration method for solving higher-order nonlinear boundary value problems using He's polynomials," International Journal of Nonlinear Sciences and Numerical Simulation, vol. 9, no. 2, pp. 141-157, 2008.

[36] M. A. Noor and S. T. Mohyud-Din, "Variational homotopy perturbation method for solving higher dimensional initial boundary value problems," Mathematical Problems in Engineering, vol. 2008, Article ID 696734, 11 pages, 2008.

[37] M. Rafei and H. Daniali, "Application of the variational iteration method to the Whitham-Broer-Kaup equations," Computers \& Mathematics with Applications, vol. 54, no. 7-8, pp. 1079-1085, 2007.

[38] N. H. Sweilam, "Harmonic wave generation in non linear thermoelasticity by variational iteration method and Adomian's method," Journal of Computational and Applied Mathematics, vol. 207, no. 1, pp. 64-72, 2007.

[39] M. Tatari and M. Dehghan, "On the convergence of He's variational iteration method," Journal of Computational and Applied Mathematics, vol. 207, no. 1, pp. 121-128, 2007.

[40] L. Xu, "He's homotopy perturbation method for a boundary layer equation in unbounded domain," Computers E Mathematics with Applications, vol. 54, no. 7-8, pp. 1067-1070, 2007.

[41] N. Herisanu and V. Marinca, "A modified variational iteration method for strongly nonlinear problems," Nonlinear Science Letters A, vol. 1, pp. 183-192, 2010.

[42] J. H. He, G. C. Wu, and F. Austin, "The variational iteration method which should be followed," Nonlinear Science Letters A, vol. 1, pp. 1-30, 2010. 


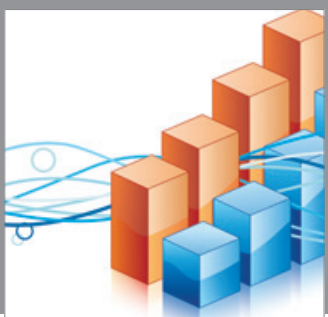

Advances in

Operations Research

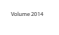

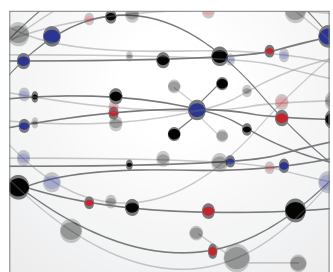

\section{The Scientific} World Journal
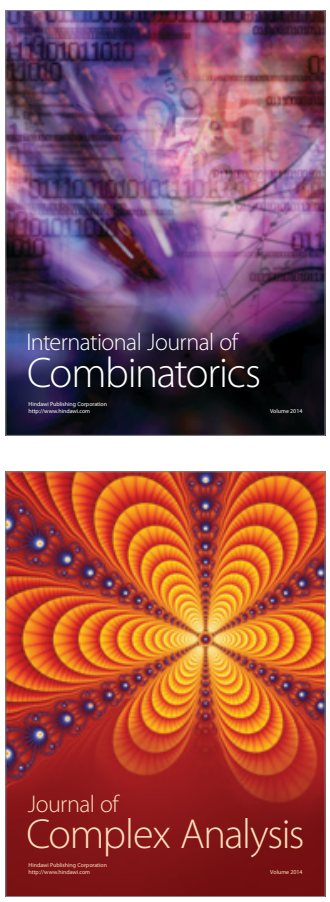

International Journal of

Mathematics and

Mathematical

Sciences
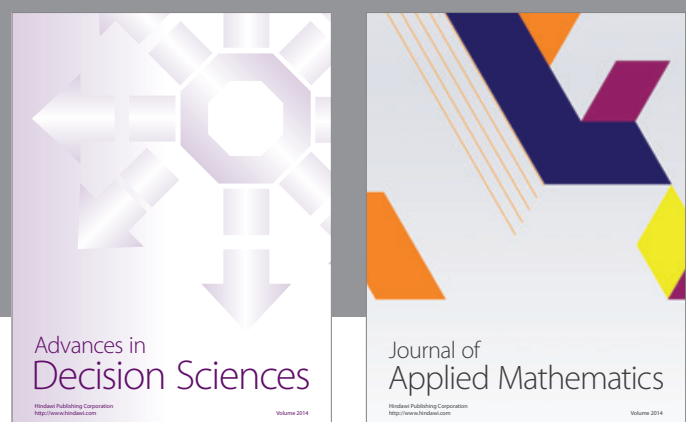

Journal of

Applied Mathematics
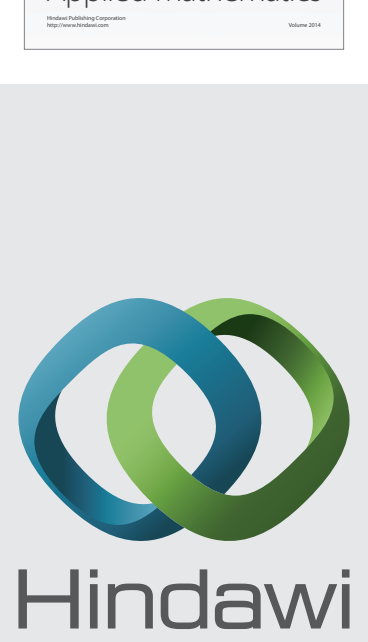

Submit your manuscripts at http://www.hindawi.com
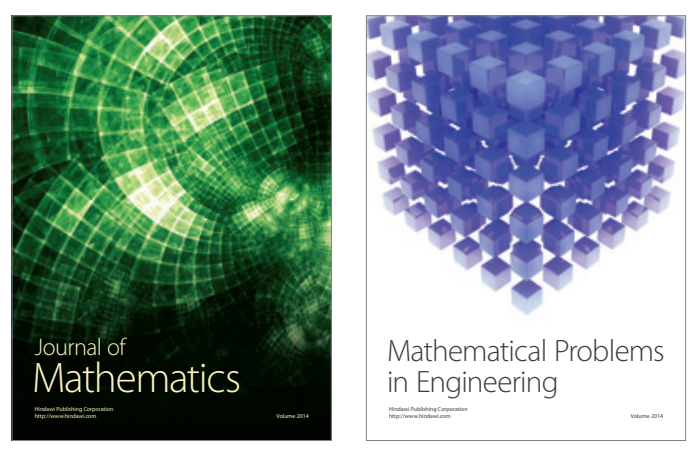

Mathematical Problems in Engineering
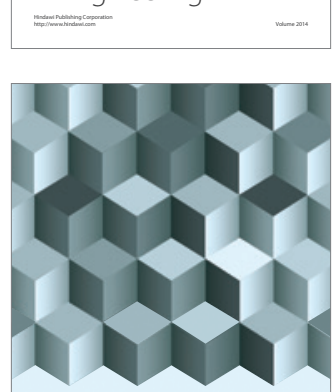

Journal of

Function Spaces
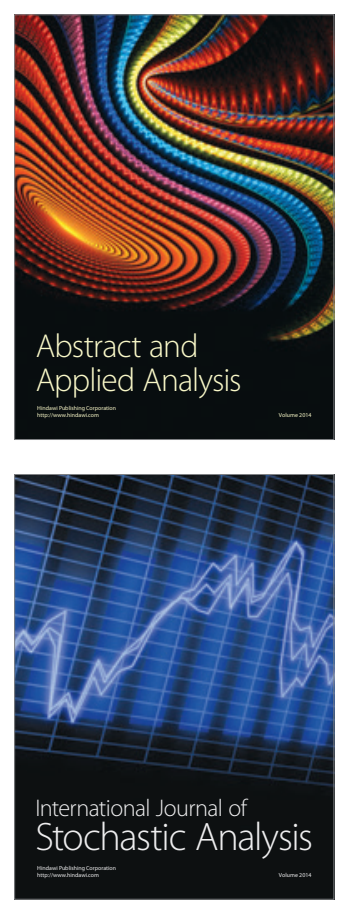

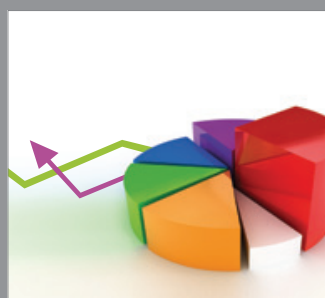

ournal of

Probability and Statistics

Promensencen
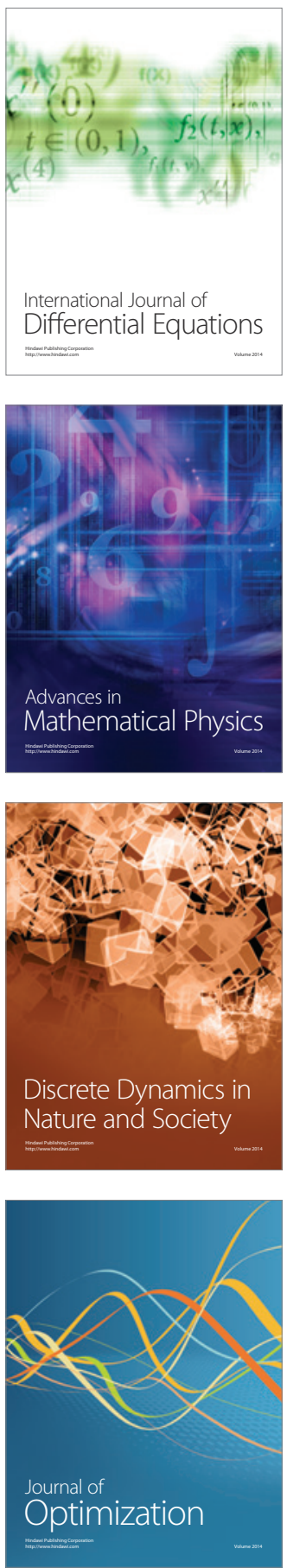